\title{
Présentation. Roman et Rhétorique aux siècles classiques
}

\section{Adrienne Petit}

\section{(2) OpenEdition \\ 1 Journals}

\section{Electronic version}

URL: http://journals.openedition.org/rhetorique/858

DOI: $10.4000 /$ rhetorique.858

ISSN: 2270-6909

\section{Publisher}

UGA Éditions/Université Grenoble Alpes

\section{Printed version}

ISBN: 978-2-37747-066-2

\section{Electronic reference}

Adrienne Petit, «Présentation. Roman et Rhétorique aux siècles classiques », Exercices de rhétorique [Online], 12 | 2019, Online since 04 February 2019, connection on 12 September 2020. URL : http:// journals.openedition.org/rhetorique/858 ; DOI : https://doi.org/10.4000/rhetorique.858

This text was automatically generated on 12 September 2020 .

\section{(c) (1) () (2)}

Les contenus de la revue Exercices de rhétorique sont mis à disposition selon les termes de la Licence Creative Commons Attribution - Pas d'Utilisation Commerciale - Partage dans les Mêmes Conditions 4.0 International. 


\title{
Présentation. Roman et Rhétorique aux siècles classiques
}

\author{
Adrienne Petit
}

\section{Le conte de Roman et Rhétorique}

1 À l'origine, c'est-à-dire en l'an II de l'empire sophistique, se rencontrèrent dame Rhétorique, aussi sérieuse qu'artificieuse, et dame Fiction, extravagante et confondante. De leurs amours interdites, nées sur les bancs du collège et scellées en secret sur ceux du tribunal, naquit le petit Roman, enfant bâtard et vigoureux. Après une enfance paisible, choyé par ses marraines Épopée et Poésie, Roman connaît une adolescence difficile. S'il a pris la faconde de Rhétorique, il entretient des rapports conflictuels avec Fiction, qui a alors mauvaise réputation. Jeune homme ambitieux, il cherche à se faire un nom et demande protection auprès de la grande Histoire qui lui ouvre les portes de la bonne société. Mais, à l'entrée dans l'âge adulte, revenu dans le giron de Fiction et plus proche que jamais d'Histoire, son amie, Roman s'éloigne peu à peu de Rhétorique. Il reproche à cette dernière ses compromissions, son conformisme et son affectation. Désormais reçu dans le grand monde et partout admiré mais honteux de ses origines oratoires, il décide alors de rompre tout lien avec sa mère nourricière. Et c'est ainsi que Roman, de bâtard, se fit orphelin.

2 Voici comment l'on pourrait rapporter à grands traits, sous la forme d'un petit conte étiologique, l'évolution des relations du genre romanesque et de l'art oratoire. Cette histoire, qui se termine ici par le reniement d'une mère par son fils, réunit en fait les récits de deux naissances successives: celle du genre romanesque, qui prendrait sa source dans l'art oratoire, et celle du roman dit «moderne », qui émergerait sur les cendres de la discipline rhétorique. 


\section{Aux origines du roman}

L'hypothèse d'une origine oratoire du roman a été proposée et étayée par plusieurs spécialistes des siècles anciens. Barbara Cassin voit dans la contemporanéité de l'essor de la seconde sophistique et du genre romanesque un indice de leur proximité, ce dernier ayant, selon elle, plus particulièrement partie liée avec l'éloge et avec l' ekphrasis dont il partage, en tant que fiction, la distance au réel et l'ornementation stylistique ${ }^{1}$. D'autres, comme Marc Fumaroli, qui déclare que « dans ses ressorts et sa genèse, le roman est une branche vivante du bien-dire ${ }^{2}$ ", soulignent la parenté du genre avec la figure de l'allégorie et avec la narration des plaidoyers fictifs, exercice qui intervient au terme de la formation rhétorique ${ }^{3}$. Cette filiation est particulièrement ostensible aux siècles classiques qui héritent d'une conception oratoire de la fiction narrative, notamment, par le truchement du modèle épique et des traductions des romans grecs qui font alors florès. Si tous les romanciers n'ont pas fait leur classe de rhétorique dans un collège jésuite, à l'instar d'Honoré d'Urfé, tous sont très fortement imprégnés d'une culture oratoire qui n'est pas circonscrite à l'espace institutionnel mais qui investit tous les domaines de la vie publique et sociale. Le roman d'Ancien Régime est ainsi modélisé par des techniques et des canevas rhétoriques allant des genres de discours aux lieux communs en passant par les figures de l'élocution. Cette modélisation s'affiche dans le paratexte, préfaces, argumentaires, titres de chapitres, manchettes, ou tables des matières qui accompagnent un certain nombre de romans de l'âge baroque et signalent des séquences textuelles par des entrées telles que sentence, description, harangue, déploration, similitude ${ }^{4} .$. À une époque où la Poétique d'Aristote se lit au prisme de sa Rhétorique, le discours poétologique sur le roman, qui se constitue peu à peu, est en effet très fortement rhétorisé. Jean Gohory intitule, par exemple, la célèbre préface du treizième livre des Amadis (1573), cycle romanesque qui a donné lieu à une anthologie de beaux discours maintes fois rééditée, « demontrance de l'art Rhetoricale qui consiste en la composition ou construction des Rommans ». Se référant à Cicéron, il y fait successivement l'éloge de l'élocution, de l'invention puis de la disposition du texte ${ }^{5}$. Dans la préface d'Ibrahim (1641), manifeste du roman héroïque, Georges Scudéry ne procède pas autrement et mobilise des catégories rhétoriques comme la variation stylistique (entre les discours et la narration), la convenance (des discours aux caractères) ou encore celle des "artifices " de rhétorique qui font l'agrément et l'intérêt de l'écriture romanesque :

ceux qui ne font qu'entasser aventures sur aventures, sans ornements, et sans exciter les passions par les artifices de la rhétorique sont ennuyeux, en pensant être divertissants. Cette narration sèche et sans art est plus d'une vieille chronique que d'un roman: qui peut bien s'embellir de ces ornements, puisque l'Histoire, toute sévère et toute scrupuleuse qu'elle est, ne laisse pas de les employer ${ }^{6}$.

Les détracteurs du genre au $\mathrm{XVII}^{\mathrm{e}}$ siècle n'auront d'ailleurs de cesse de renvoyer et réduire le roman à ses origines rhétoriques ${ }^{7}$, à l'instar de Charles Sorel qui déclare que le nom de roman, désignant un mélange de langue romaine et gauloise, convient très bien à des livres qui « ne contiennent que langage ; Je veux dire que l'on n'y aprend que des compliments \& des amourettes ${ }^{8} »$.

Contemporaine du renouveau des études rhétoriques, l'affirmation de cette généalogie va pourtant à l'encontre d'un autre récit, selon lequel le genre romanesque dans son essence, c'est-à-dire le roman "moderne", se serait constitué contre une discipline oratoire déclinante. L'histoire du genre romanesque serait ainsi tendue entre une 
polarité rhétorique, qui trouverait son plein accomplissement aux siècles classiques, et une polarité poétique, qui s'imposerait avec le roman flaubertien et l'apparition d'une langue littéraire. Cette représentation et un préjugé anti-rhétorique n'ont pas laissé d'orienter l'appréciation des romans d'Ancien Régime. Aussi la réussite d'une œuvre at-elle pu être évaluée à l'aune du degré d'émancipation qu'elle manifeste envers les cadres rhétoriques et de l'expression d'une défiance envers les séductions de la parole. L'article de Ralph A. York sur "La Rhétorique dans L'Astrée ${ }^{9}$ » affirme de la sorte la supériorité du roman d'Urfé, sur les fictions sentimentales qui le précèdent, en arguant du caractère non-rhétorique de sa narration, de la subordination des passages oratoires (dont relèvent les discours des personnages) à une fonction narrative et d'un traitement parodique des figures de style. De même, la mise en scène critique de l'inefficience, des ridicules ou des dangers du discours éloquent, notamment dans la tradition du roman comique, est fréquemment corrélée à la mise en valeur de la «modernité » supposée du texte. Les Lettres portugaises ou encore La Princesse de Clèves, que l'on a lus comme la mise en question de la rhétorique des passions baroque ${ }^{10}$, en sont des exemples particulièrement célèbres.

\section{Pour une lecture rhétorique du genre romanesque}

5 La perte progressive du "regard rhétorique ${ }^{11}$ " associée au développement d'une théorie formelle du récit ainsi que la complexité énonciative du roman ont sans nul doute contribué à occulter, un temps durant, les liens qui l'unissaient à l'art oratoire. Dans son ouvrage pionnier paru en 1970, Rhétorique et Littérature, Aron Kibédi Varga fait état de la difficulté à assigner le roman à un genre du discours, à la différence du théâtre et de la poésie qui seraient plus immédiatement appréhendables à partir d'une grille rhétorique :

[...] du moment où il essaie de se libérer de l'épopée pour devenir un genre autonome, le roman pose des problèmes insolubles dans notre perspective : de tous les genres littéraires, c'est le roman au sens moderne - sens qui, d'ailleurs, n'est plus tout à fait «moderne» - du terme qui semble s'éloigner le plus des conceptions et méthodes traditionnelles de la rhétorique. Celle-ci contient des préceptes que le dramaturge, le poète lyrique et le poète épique adapteront sans peine à leur matière ; elle peut fournir encore certaines techniques pour des points de détail : un portrait, un discours, une conversation mais non pas pour l'ensemble $\mathrm{du}$ roman, et notamment pour cette partie essentielle qui est la narration romanesque. Pour la rhétorique, le récit est toujours un prétexte, surtout un prétexte à l'éloge. Il est significatif que Marmontel, dans son article Description [des Éléments de littérature] ne traite que les descriptions «en poésie et en éloquence ». Par conséquent, si le roman avait peu de crédit aux yeux des érudits de l'époque, ce n'est pas seulement parce que les modèles antiques manquaient mais aussi, peutêtre, parce que sa situation ne correspondait finalement à aucune situation rhétorique. Dans une littérature d'inspiration rhétorique il n'y a pas de place pour le roman. Aussi, à partir de Mme de Lafayette, l'histoire du roman constitue-t-elle la partie principale de l'histoire de la libération progressive de la littérature des contraintes de la rhétorique; les autres genres, moins gênés par la rhétorique, ne suivront cet exemple qu'avec un retard considérable ${ }^{12}$.

La position d'A. Kibédi Varga est à la fois représentative d'une conception "moderne » du roman et d'une manière d'envisager l'approche rhétorique de la littérature en termes de "rhétoricité13 ", c'est-à-dire d'orientation argumentative, plutôt que d'histoire des formes. La difficulté de l'entreprise, qui visait à dégager des 
correspondances entre genres rhétoriques et genres littéraires en vertu de leurs finalités argumentatives (conseiller/dissuader, louer/blâmer, disculper/inculper), réside à la fois dans son caractère systématique et dans son degré de généralité, les trois genres du discours n'étant que des catégories théoriques se déclinant, en pratique, en une multitude de discours institués ${ }^{14}$. En effet, dès lors que l'on étudie les genres oratoires insérés, représentant un pourcentage très important dans un certain nombre de fictions d'Ancien Régime, la lecture rhétorique s'avère particulièrement productive. En témoignent, pour n'en citer que quelques-uns, les travaux de Georges Molinié sur la plainte dans les fictions de l'âge baroque, de Delphine Denis sur la conversation dans le roman scudéryen, de Roberto Romagnino sur la description ou encore d'Adeline Desbois-Ientile et d'Ellen Delavallée sur les discours dans Les Illustrations de Gaule de J. Lemaire de Belges ${ }^{15}$. Le fonctionnement de la narration elle-même, qui n'est pas le seul apanage du genre épidictique mais une séquence textuelle tendue vers une démonstration ${ }^{16}$, peut être éclairé par une lecture rhétorique, qu'elle se présente comme le discours d'un narrateur-orateur, qu'elle recoure à des procédés argumentatifs divers, comme l'amplification ${ }^{17}$, ou qu'elle s'anime de figures de rhétorique. Il reste que la saisie rhétorique du roman, genre énonciativement mixte, doit se confronter à l'hybridité d'un genre qui fait se succéder et enchâsse les discours, transpose et adapte, plus ou moins librement, des séquences et modèles oratoires, comme le relève Christine Noille :

Nous avouerons volontiers qu'entre la modélisation structurale initiée par la pratique des genres du discours et une modélisation générale de la structuration syntagmatique des textes, telle qu'on peut la déduire de catégorisations a priori, il nous manque encore des modèles empiriques qui nous permettent d'expérimenter, sur le terrain du roman en particulier, la variété énonciative en continuité avec la variation discursive ${ }^{18}$.

C'est là toute la plasticité du genre romanesque et tout l'enjeu du présent numéro.

\section{Le retour de l'enfant prodigue}

Depuis l'ouvrage d'A. Kibédi Varga, de nombreux travaux ont progressivement réouvert la voie à une approche rhétorique de la fiction narrative, à la faveur de l'essor des recherches sur l'ancienne discipline du discours. L'objectif de ce numéro, qui réunit les contributions de spécialistes de la fiction narrative, est d'apprécier la façon dont l'art oratoire informe et modélise, à différentes échelles, l'écriture et la lecture du roman aux siècles classiques. Les articles qui le composent mettent en valeur l'extraordinaire richesse rhétorique du genre romanesque, propre à accueillir différents genres de discours relevant aussi bien de l'éloquence judiciaire, religieuse et politique que de l'éloquence mondaine. Selon Pascale Mounier, L'amant desconforté cherchant confort parmy le monde (1529) d'Antoine Prévost, de formation juridique, prend ainsi la forme de discours pro et contra l'amour et les femmes, rappelant l'exercice des suasoires dont le genre romanesque serait issu. S'intéressant plus particulièrement à l'argument d'autorité qui permet l'élaboration d'une norme éthique, la chercheuse montre que le roman se présente comme "un réservoir de preuves prêtes à l'emploi ", exhibées et extraites au moyen de manchettes. De la Renaissance à la fin du xix siècle, plusieurs contributions mettent en avant cette fonction d'encyclopédie des formes oratoires (genres de discours, lieux communs, styles et figures) qui peuvent être signalées par différents appareillages éditoriaux. École de rhétorique, le genre romanesque est aussi un laboratoire d'éloquence, comme le fait valoir Suzanne Duval 
dans son article sur les lettres enchâssées dans les fictions narratives de l'âge baroque, qui constituent un trésor de lieux communs amoureux. L'autrice met en évidence que la lettre amoureuse, peu théorisée par les manuels d'épistolographie, est l'un des lieux où s'élabore une rhétorique mondaine qui s'émancipe des cadres scolaires, en promouvant un style naturel.

7 Aussi, loin de la monotonie que l'on a pu imputer à la langue oratoire des romans d'Ancien Régime, plusieurs contributeurs insistent a contrario sur la variété stylistique qui caractérise le genre romanesque, en lien étroit avec sa nature polyphonique. À partir de l'étude de deux exhortations et d'une remontrance du Polexandre, Roberto Romagnino met en avant le talent oratoire de Gomberville qui propose autant de modèles d'éloquence du prince. Cette variation diastratique, du style simple au style élevé en passant par le style moyen, distingue le discours politique du discours amoureux (qui ne varie guère) et s'incarne en différents personnages, à l'instar du triptyque homérique formé par Ulysse, Nestor et Ménélas, tout en participant à leur caractérisation morale. La diversité de styles peut se déployer au sein du même texte ou encore entre des textes apparentés par un même hypotexte. Analysant deux versions romancées du livre IV de l'Énéide parues dans la seconde moitié du XVI e siècle, Jean Lecointe fait la démonstration qu'elles mettent en œuvre des options stylistiques différenciées. Tandis que la réécriture de Valentinian est placée sous le signe de l'abréviation, celle d'Hélisenne de Crenne amplifie considérablement le texte-source, l'imitation de Virgile constituant alors pour les romanciers « une école de l'expression affective ».

8 Au-delà des procédés d'écriture, il était nécessaire d'envisager les pratiques lectoriales qui accompagnent ou qui sont directement induites par la modélisation rhétorique du roman: lecture à voix haute, lecture silencieuse et lecture commentée. Mathilde Faugère interroge la pertinence du modèle rhétorique de la conversation pour penser la lecture d'un genre, qui favorise l'isolement et se caractérise par une désinstanciation énonciative. L'étude du Roman des lettres (1667) de l'abbé d'Aubignac, qui propose une mise en abyme de la lecture romanesque, et de la correspondance de Mme de Sévigné, qui rapporte plusieurs de ses expériences de lectrice, montre que plusieurs formes de réception coexistent et que le lecteur de roman ne peut être décrit comme un simple auditeur.

9 L'ensemble des contributions, qui couvrent un corpus de romans allant du XVI ${ }^{e}$ au XIX siècle, font apparaître que les inflexions formelles du roman sont corrélées aux vicissitudes de l'art oratoire et qu'elles s'inscrivent dans un contexte épistémique, historique et social donné. Il n'est ainsi pas anodin, bien que fortuit, que les deux articles qui portent sur le XvIII ${ }^{\text {e }}$ siècle soient consacrés à des textes dans lesquels la rhétorique est explicitement dirigée contre le roman. Alors que le siècle des Lumières s'est ouvert sur la "grande querelle de rhétorique ${ }^{19}$ ", les romans apologétiques témoignent d'une disqualification des passions et de l'imagination qui tranche avec la formule du roman dévot à la Camus, qui entendait se servir des séductions de l'éloquence contre celles de la fiction. S'intéressant aux romancières antiphilosophes qui publient dans les années 1770-1790, Agathe Mezzadri-Guedj démontre que la rhétorique chrétienne de Marie-Françoise Loquet dans Cruzamante (1786) vise, à travers Fénelon, le modèle romanesque et le quiétisme dont il est la figure emblématique. Dans Le Doyen de Killerine (1735-1740), ce refus du romanesque prend la forme d'un envahissement $d u$ récit par d'austères discours argumentatifs. Pour Lise Charles, ce 
refus, lié au rapprochement de Prévost avec les jésuites, s'accompagne d'une mise en scène de l'échec de la parole qui engage une remise en question de la rhétorique ellemême.

10 À l'instar de ces deux contributions, qui témoignent du rejet d'un régime poétique au profit d'un régime rhétorique du roman, plusieurs articles complexifient et nuancent, d'une part, la thèse du passage d'un régime à l'autre et invalident, d'autre part, sa visée téléologique. Tandis que J. Lecointe propose de voir dans le glissement de la fiction sentimentale à la nouvelle historique l'évolution d'une rhétorique du pathos à l'autre, Mercedes Blanco s'inscrit en faux contre l'idée que le roman de Cervantès, du fait de sa visée comique et subversive, s'affranchirait des cadres rhétoriques. Non seulement la compétence oratoire y est universellement partagée entre les personnages mais Cervantès déploie un art consommé de la controverse qui, volontiers ironique ou parodique, fait toute la grandeur et le panache de l'orateur Don Quichotte. Sans remettre en cause l'originalité de l'œuvre de Cervantès, dont l'autrice loue le génie oratoire, ce constat pose la question de la représentation a-rhétorique voire antirhétorique du roman moderne. Dans la dernière contribution de ce volume, Christelle Reggiani répond, par un jeu d'échos, à cette remise en cause en réaffirmant la pertinence de l'héritage oratoire à l'époque du déclin de la discipline. Si le roman du $\mathrm{XIX}^{\mathrm{e}}$ siècle propose une satire des discours politiques, il demeure un "conservatoire " des formes rhétoriques qui atteste la vitalité de la parole éloquente, celle-ci fût-elle moquée ou détournée. S'inscrivant dans un contexte post-révolutionnaire, cette posture antirhétorique, traduisant notamment un refus de l'autorité, tient moins dès lors à des raisons esthétiques que politiques.

11 Ce volume, qui rassemble plusieurs générations de chercheuses et de chercheurs, dont les travaux ont formé les autres (parmi lesquels je me compte), témoigne du renouvellement de l'intérêt pour une approche rhétorique de la fiction narrative et de l'évolution récente des rapports du genre romanesque à l'art oratoire. La publication de deux romans à succès mettant en scène de longues et héroïques joutes oratoires, $L a$ Horde du Contrevent (2004) d'Alain Damasio et La Septième fonction du langage (2015) de Laurent Binet, me semble à cet égard tout à fait révélatrice. Bien des pistes restent assurément à explorer, tant sur le plan de l'analyse textuelle que sur les plans théorique et historique. Des corpus comme ceux des romans néo-latins et des romans des $\mathrm{Xx}^{\mathrm{e}}$ et $\mathrm{xxI}^{\mathrm{e}}$ siècles, certains dispositifs éditoriaux et pratiques lectoriales comme celles qui reposent sur l'indexation de séquences oratoires, ou encore, d'un point de vue méthodologique, l'interaction des approches rhétoriques et narratologiques constituent autant de terrains et d'axes de recherche prometteurs.

$\mathrm{Au}$ terme de ce travail, je voudrais remercier les contributrices et contributeurs d'avoir répondu à mon invitation. Je tiens également à exprimer toute ma gratitude à Francis Goyet et à Christine Noille pour leur travail de relecture et pour la confiance qu'ils m'ont accordée. 


\section{BIBLIOGRAPHY}

Bury, Emmanuel, « À La recherche d'un genre perdu : le roman et les poéticiens du XVII siècle », Perspectives de la recherche sur le genre narratif français du XVII e siècle, actes du colloque de Pavie (octobre 1998), Pise-Génève, Edizioni Ets-Éditions Slatkine, n 8, 2000, p. 9-33.

Cassin, Barbara, L'Effet sophistique, Paris, Gallimard, 1995.

Charles, Michel, Rhétorique de la lecture, Paris, Seuil, 1977.

Denis, Delphine, La Muse galante. Poétique de la conversation dans l'œuvre de Madeleine Scudéry, Honoré Champion, Paris, 1997.

Desbois-Ientile, Adeline, Lemaire de Belges, Homère belgeois. Le mythe troyen à la Renaissance, Paris, Classiques Garnier, 2019 (sous presse).

Duval, Suzanne, « L'écriture romanesque, un prolongement de la classe de rhétorique ?

L'exemple de L'Astrée d'Honoré d'Urfé ", Maîtres et Élèves de la Renaissance aux Lumières, Th. Catel, C. Fournial, A. Petit (dir.), Actes de la journée d'études des jeunes chercheurs du CELLF, Université Paris-Sorbonne, 16 juin 2012, en ligne à l'URL : http://www.cellf.paris-sorbonne.fr/ journee-detude/maitres-et-eleves-de-la-renaissance-aux-lumieres.

Duval, Suzanne, « Romanesque et amplification : l'écriture de la circonstance dans l'aventure fictionnelle du premier XVII ${ }^{\mathrm{e}}$ siècle », Exercices de rhétorique [En ligne], 4 | 2014, URL : http:// journals.openedition.org/rhetorique/353.

Fumaroli, Marc (dir.), Histoire de la rhétorique dans l'Europe moderne 1450-1950, Paris, P.U.F., 1999.

Fumaroli, Marc, L'Âge de l'éloquence, Rhétorique et "res literaria", de la Renaissance au seuil de l'époque classique, Albin Michel, Paris, 1994.

Goyet, Francis, «Le problème de la typologie des discours », Exercices de rhétorique [En ligne], 1 | 2013, URL : http://rhetorique.revues.org/122.

Goyet, Francis, Le Regard rhétorique, Paris, Classiques Garnier, 2017.

Kibédi Varga, Aron, Rhétorique et Littérature. Études de structures classiques, Paris, Klincksieck, 2002 [1970].

Lecointe, Jean, « Lectures romanesques de Virgile à la Renaissance ", Cahiers de l'Association internationale des études françaises, 2001, n 53, p. 191-212.

Mal-Maeder, Danielle van, La Fiction des déclamations, Leyde-Boston, Brill, 2007.

Mathieu-Castellani, Gisèle, La Rhétorique des passions, Paris, PUF, 2000.

Molinié, Georges, Du roman grec au roman baroque, Toulouse, Presses Universitaires du Mirail, 1982.

Mounier Pascale, Le Roman humaniste : un genre novateur français (1532-1564), Paris, Honoré Champion, 2007.

Noille, Christine, « Les genres du discours dans l'ancienne rhétorique : listes, schémas et mode d'emploi, avec un exemple (le discours de Germanicus) », Exercices de rhétorique [En ligne], 3 | 2014, §7, URL : http://journals.openedition.org/rhetorique/337).

Noille, Christine, « Narratio / Narration? La rhétorique et la langue française », Littératures classiques, D. Denis, C. Barbafieri et L. Susini (dir.), vol. 96, n 2, 2018, p. 85-97. 
Pelous, Jean-Michel, « Une héroïne romanesque entre le naturel et la rhétorique : le langage des passions dans les Lettres Portugaises ", Le Roman au XVII siècle, Revue d'Histoire Littéraire de la France (RHLF), n³-4, 1977, p. 554-563.

Petit, Adrienne, Le Discours romanesque des passions. Rhétorique et poétique des passions dans la fiction narrative en prose $\mathrm{du} \mathrm{XVII}^{e}$ siècle, thèse sous la direction de Delphine Denis, soutenue le 15 octobre 2016.

Reggiani, Christelle, L'Éloquence du roman. Rhétorique, littérature et politique aux XIXe et XXe siècles, Genève, Droz, 2008.

Romagnino, Roberto, Décrire dans le roman de l'âge baroque (1585-1660) : formes et enjeux de l' ecphrasis, Paris, Classiques Garnier, à paraître.

Sermain, Jean-Paul, Rhétorique et Roman au XVIII siècle, Oxford, Voltaire foundation, 1985.

York, Ralph A., « La Rhétorique dans L'Astrée », XVII siècle, n 110-111, 1976, p. 3-24.

\section{NOTES}

1. B. Cassin, L'Effet sophistique, Paris, Gallimard, 1995.

2. M. Fumaroli, «Préface " de L'Âge de l'éloquence, Rhétorique et "res literaria", de la Renaissance au seuil de l'époque classique, Paris, Albin Michel, 1994, p. IX.

3. Sur cette pratique, voir D. van Mal-Maeder, La Fiction des déclamations, Leyde-Boston, Brill, 2007.

4. Toutes ces entrées figurent dans la table des matières qui accompagne l'édition des Éthiopiques d'Héliodore paru en $1588 \mathrm{chez}$ Thomas Mallard et se retrouvent peu ou prou dans un certain nombre de romans de l'âge baroque.

5. Voir P. Mounier, Le Roman humaniste : un genre novateur français (1532-1564), Paris, H. Champion, 2007, p. 118-119.

6. G. de Scudéry, «Préface » d'Ibrahim dans C. Esmein-Sarrazin éd., Poétiques du roman. Scudéry, Huet, Du Plaisir et autres textes théoriques et critiques du XVII siècle sur le genre romanesque, Paris, H. Champion, 2004, p. 142.

7. À ce propos, voir E. Bury, «À La recherche d'un genre perdu : le roman et les poéticiens du $\mathrm{XVII}^{\mathrm{e}}$ siècle ", dans Perspectives de la recherche sur le genre narratif français du XVII ${ }^{e}$ siècle, actes du colloque de Pavie (octobre 1998), Pise-Genève, Edizioni Ets - Éditions Slatkine, 2000, p. 9-33.

8. Ch. Sorel, Remarques sur les XIIII Livres du berger extravagant. Où les plus extraordinaires choses qui s'y voient, sont appuyées de diverses authoritez, \& où l'on treuve des recueils de tout ce qu'il y a de remarquable dans les Romans, \& dans les ouvrages poëtiques, avec quelques autres observations, tant sur le langage, que sur les avantures, Paris, T. du Bray, 1628, p. 10.

9. R. A. York, « La Rhétorique dans L'Astrée », XVII e siècle, n 110-111, 1976, p. 13-24.

10. Voir J.-M. Pelous « Une héroïne romanesque entre le naturel et la rhétorique : le langage des passions dans les Lettres Portugaises ", Revue d'Histoire Littéraire de la France, n 3-4, 1977, Le Roman au XVII siècle, p. 554-563 ; et A. Petit «Un langage du cœur sans les artifices du style. Les Lettres à Madame Marquise sur La Princesse de Clèves (1678) de J.-B. de Valincour» dans C. Ramond et V. Ferrer dir., La Langue des émotions, Paris, Classiques Garnier, 2017, p. 43-59.

11. Fr. Goyet, Le Regard rhétorique, Paris, Classiques Garnier, 2017.

12. A. Kibédi Varga, Rhétorique et Littérature. Études de structures classiques, Paris, Klincksieck, 2002 [1970], p.97-98. Pour le critique, la poésie lyrique serait globalement assimilable à une scène d'énonciation délibérative tandis que le genre tragique serait proche du judiciaire. 
13. Sur le concept de «rhétoricité » désignant une « rhétorique fondamentale " par opposition à une "rhétorique instrumentale», voir Ph.-J. Salazar, "De l'éloquence à la rhétoricité, trente années fastes ", XVII siècle, $\mathrm{n}^{\circ}$ 236, 2017, p. 421-426.

14. Comme le rappelle Christine Noille dans « Les genres du discours dans l'ancienne rhétorique : listes, schémas et mode d'emploi, avec un exemple » (Exercices de rhétorique, 3|2014, § 7, URL : http://journals.openedition.org/rhetorique/337) : «Nous ajouterons simplement qu'entre les genera dicendi et les species orationis, la différence n'est pas de l'ordre de la modulation ni de l'application: les premiers relèvent de postulats et les seconds de l'usus. Les premiers sont opératoires au niveau de la théorie ; mais seuls les seconds interviennent dans la pratique, qu'il s'agisse de l'art d'écrire ou de l'art de lire. »

15. G. Molinié, Du roman grec au roman baroque, Toulouse, Presses Universitaires du Mirail, 1982 ; D. Denis, La Muse galante. Poétique de la conversation dans l'œuvre de Madeleine Scudéry, H. Champion, Paris, 1997 ; R. Romagnino, Décrire dans le roman de l'âge baroque (1585-1660) : formes et enjeux de l' ecphrasis, Paris, Classiques Garnier, à paraître; A. Desbois-Ientile, Lemaire de Belges, Homère belgeois. Le mythe troyen à la Renaissance, Paris, Classiques Garnier, 2019 (sous presse) ; E. Delvallée, "Lemaire de Belges traducteur de l'Iliade: les discours du chant III dans les Illustrations", Exercices de rhétorique, 3 | 2014, URL : http://rhetorique.revues.org/210.

16. Voir Ch. Noille, "Narratio / Narration? La rhétorique et la langue française ", Littératures classiques, D. Denis, C. Barbafieri et L. Susini dir., vol. 96, nº 2, 2018, p. 85-97.

17. Sur l'utilisation de l'amplification par les romanciers de l'âge baroque, voir S. Duval, "L'écriture romanesque, un prolongement de la classe de rhétorique? L'exemple de L'Astrée d'Honoré d'Urfé », dans Th. Catel, C. Fournial, A. Petit dir., Maîtres et Élèves de la Renaissance aux Lumières, Actes de la journée d'études des jeunes chercheurs du CELLF, Université ParisSorbonne, 16 juin 2012, en ligne à l'URL : http://www.cellf.paris-sorbonne.fr/journee-detude/ maitres-et-eleves-de-la-renaissance-aux-lumieres ; et S. Duval, « Romanesque et amplification : l'écriture de la circonstance dans l'aventure fictionnelle du premier xvII siècle », Exercices de rhétorique, 4 | 2014, URL : http://journals.openedition.org/rhetorique/353.

18. Ch. Noille, « Les genres du discours dans l'ancienne rhétorique », op. cit., § 71 .

19. Sur cette querelle, voir notamment B. Munteano, Constantes dialectiques en littérature et en histoire, problèmes, recherches, perspectives, Paris, Didier, 1967, p.355-365; et Volker Kapp, "L'apogée de l'atticisme français ou l'éloquence qui se moque de la rhétorique », dans M. Fumaroli dir., Histoire de la rhétorique dans l'Europe moderne 1450-1950, Paris, P.U.F., 1999, p. 707-786.

\section{AUTHOR}

\section{ADRIENNE PETIT}

Université de Lille - EA 1061 (Analyses littéraires et histoire de la langue) 